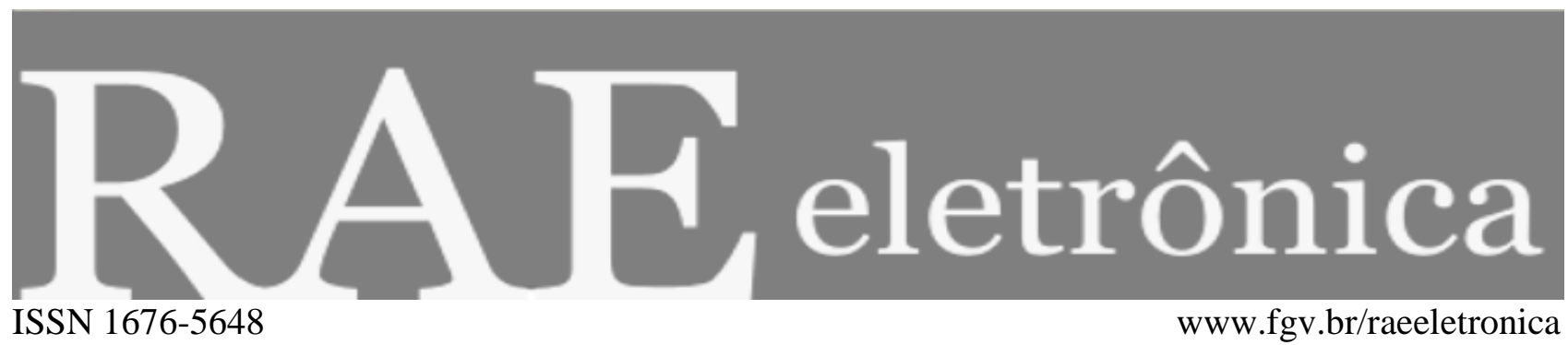

ISSN 1676-5648

wWw.fgv.br/raeeletronica

\title{
ARTIGOS
}

\section{ANÁLISE DO DESEMPENHO ECONÔMICO-FINANCEIRO DE EMPRESAS DE SAÚDE}

\section{ANALYSIS OF THE ECONOMIC AND FINANCIAL PERFORMANCE OF HEALTH COMPANIES}

ANÁLISIS DEL DESEMPEÑO ECONÓMICO-FINANCIERO DE LAS EMPRESAS DE SALUD

\section{Germany Gonçalves Veloso}

Doutorando em Administração pela Escola de Administração de Empresas, Fundação Getulio Vargas São Paulo - SP, Brasil

germanyveloso@hotmail.com

\section{Ana Maria Malik}

Professora da Escola de Administração de Empresas de São Paulo, Fundação Getulio Vargas - São Paulo - SP, Brasil ana.malik@fgv.br

Recebido em 31.08.2008. Aprovado em 26.03.2010. Disponibilizado em 16.04.2010

Avaliado pelo sistema double blind review

Editor Científico: Mariângela Leal Cherchiglia

RAE-eletrônica, v. 9, n. 1, Art. 2, jan./jun. 2010.

http://www.rae.com.br/eletronica/index.cfm?FuseAction=Artigo $\& I D=5573 \&$ Secao=ARTIGOS $\&$ Volume $=9 \&$ Numero $=1 \&$ $\mathrm{Ano}=2010$

CCopyright 2010 FGV-EAESP/RAE-eletrônica. Todos os direitos reservados. Permitida a citação parcial, desde que identificada a fonte. Proibida a reprodução total. Em caso de dúvidas, consulte a Redação: raeredacao@fgv.br; 55 (11) 3799-7898.

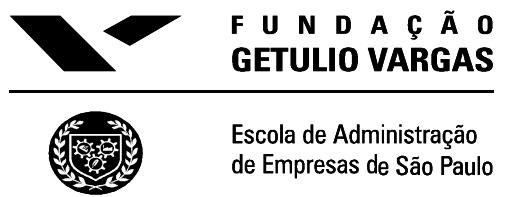




\section{RESUMO}

O objetivo do artigo é avaliar o desempenho econômico-financeiro de empresas da área de Saúde, principalmente sua rentabilidade, comparando hospitais, operadoras de planos de saúde e empresas em geral. Foram usados dados dos balanços financeiros do exercício de 2006 compilados da publicação Balanço Anual 2007 da Gazeta Mercantil. Os dados foram comparados utilizando-se os testes não paramétricos da mediana e do qui quadrado. Comparando-se as maiores empresas de cada categoria, seus retornos sobre o ativo total não têm diferenças estatísticas significantes. Os maiores hospitais e operadoras tiveram lucratividade igual entre si, porém inferior à das empresas em geral. Os hospitais tiveram lucros antes de juros, impostos, depreciação e amortização (LAJIDA) maior e cresceram menos que as operadoras em 2006. Conclusão: a rentabilidade de hospitais com maiores receitas não parece diferir significantemente da de outras empresas da economia. Adicionalmente, observou-se que não existe distinção significante entre hospitais com e sem finalidade lucrativa, no que diz respeito à margem LAJIDA, margem líquida e retorno sobre ativos totais.

PALAVRAS-CHAVE Hospitais, operadoras de planos de saúde, rentabilidade, lucratividade, LAJIDA.

ABSTRACT The aim of this paper is to evaluate the economic and financial performance, and particularly the return on investment, of companies operating in the health sector, by comparing hospitals, health plan operators and businesses in general. The data used was taken from financial statements for the year 2006, as compiled by Gazeta Mercantil's publication, 'Annual Report 2007'. Data were compared using the non-parametric median and chi square tests. When the largest companies in each category are compared, there are no statistically significant differences in their returns on total assets. The largest hospitals and health plan operators were equally profitable, but less profitable than business in general. Hospitals had a bigger earnings before interest, taxes, depreciation, and amortization (EBITDA) but grew less than operators in 2006. The conclusion reached is that the return on investment of hospitals with large revenues does not seem to differ significantly from that of other companies in the economy. It was also observed that there is no significant difference between for-profit or not-for-profit hospitals, with respect to their EBITDA margin, net margin and return on total assets.

KEYWORDS Hospitals, health plan operators, return on investment, profitability, EBITDA.

RESUMEN El objetivo del artículo es evaluar el desempeño económico-financiero de las empresas del sector de Salud, principalmente su rentabilidad, comparando hospitales, operadoras de planes de salud y empresas en general. Fueron usados datos de los balances financieros del ejercicio de 2006, compilados de la publicación Balanço Anual 2007 de la Gazeta Mercantil. Los datos fueron comparados utilizando las pruebas no paramétricas de la mediana y del chi cuadrado. Comparando las mayores empresas de cada categoría, su rendimiento sobre activos totales no tiene diferencias estadísticas significativas. Los mayores hospitales y operadoras tuvieron lucratividad igual entre sí, pero inferior a la de las empresas en general. Los hospitales tuvieron ganancia antes de intereses, impuesto, depreciación y amortización (EBITDA) mayor y crecieron menos que las operadoras en 2006. Conclusión: la rentabilidad de hospitales con mayores lucros no parece diferir significativamente de la de otras empresas de la economía. Adicionalmente, se observó que no existe distinción significativa entre hospitales con y sin finalidad lucrativa, en lo que se refiere al margen EBITDA, margen líquido y rendimiento sobre activos totales.

PALAVRAS CLAVE Hospitales, operadoras de planes de salud, rentabilidad, lucratividad, EBITDA. 


\section{UM MERCADO EM MOVIMENTO}

Nos últimos anos, os processos de abertura de capital de empresas em geral e da área de Saúde em particular têm aumentado. Na verdade, as ofertas públicas de ações - Initial Public Offerings (IPOs) no ano de 2007 foram recorde até então. Entre essas ofertas, verifica-se a entrada na Bolsa de Valores de algumas empresas da área de Saúde, marcadamente algumas operadoras de planos de saúde (OPS) e empresas de medicina diagnóstica (EMD). Em função disso, alguns investidores começam a se interessar pela possibilidade de cadeias de hospitais ou mesmo hospitais isolados estarem um dia, também, listados na Bovespa. Paralelamente a isso, administradores de hospitais privados ligados a sociedades anônimas de capital fechado frequentemente também são abordados por potenciais investidores, ou mesmo acionistas, interessados em saber se hospitais são realmente empreendimentos rentáveis. Observa-se ainda o crescente interesse de fundos de participações (private equity) em investir em hospitais com a intenção de, alguns anos após a compra, também realizar venda ou abertura de capital. E, principalmente, os hospitais privados continuam a ser abertos, desafiando duas premissas comuns do setor (VECINA NETO; MALIK, 2007): que este tipo de empresa não é rentável e que a tendência na área hospitalar é a redução no numero de leitos. Por exemplo, na cidade de São Paulo, de novembro de 2007 a março de 2008, pelo menos três unidades hospitalares foram inauguradas no município: o Hospital São José, vinculado à Beneficência Portuguesa de São Paulo; o Hospital VillaLobos, um hospital geral pertencente a um grupo que se dedica à especialidade de otorrinolaringologia, e o Hospital Anália Franco, terceira unidade do Hospital São Luiz. Todos privados e vinculados a grupos de assistência médica considerados bem-sucedidos.

Paralelamente a isso, quase todos os maiores hospitais privados de São Paulo também estão se expandindo. Têm grandes projetos de ampliação do número de leitos em andamento. Além disso, muitos abriram as chamadas "unidades avançadas", que são unidades ambulatoriais e, ocasionalmente, de pronto atendimento. Elas prestam serviços menos complexos e encaminham pacientes aos serviços que as criaram, melhorando dessa forma os resultados operacionais e financeiros da rede de que fazem parte.

Ao mesmo tempo, os hospitais são organizações com grande impacto social. Tipicamente geram empregos e oportunidades, pois são muito dependentes de mão de obra. Além disso, trazem renda a fornecedores e a todo tipo de empresas de serviços à sua volta. Grandes hospitais privados muitas vezes trazem melhoria ao próprio setor, quando disseminam conhecimento médico e administrativo, 
divulgando filosofias, técnicas gerenciais e a busca da excelência na qualidade de atendimento. Mesmo quando pequenos, geram empregos dentro e fora do setor (CORREA, 2009). Por outro lado, os hospitais são caros. Trata-se de empreendimentos que exigem grandes investimentos em instalações e equipamentos, e apresentam, enquanto negócios, um longo tempo de maturação.

Uma interrogação frequente nesse mercado é se é possível fazer avaliação dos resultados econômico-financeiros dos hospitais como um todo, uma vez que muitos deles são hospitais sem finalidades lucrativas (HSFL). Ou se caberia análise somente daqueles hospitais organizados para explorar atividade econômica, os hospitais com finalidade lucrativa (HCFL). Essas dúvidas são de profissionais da área de Saúde - frequentes investidores em hospitais de médio porte ou em clínicas - e de interessados em geral.

Pela complexidade da atividade hospitalar, pelos diferentes tipos de relação existentes entre os diversos agentes envolvidos, pelo número cada vez maior de stakeholders identificados em relação à área, pelo tempo de maturação e mesmo pelo fato de a atividade hospitalar ter sido vista por muito tempo dissociada das questões relativas à lucratividade e rentabilidade, os investidores são muito cautelosos em relação à sua entrada no setor. Em função disso, considerou-se adequado examinar o desempenho das empresas de saúde em relação à sua atratividade como investimento, de maneira a permitir decisões mais fundamentadas.

O objetivo deste trabalho, portanto, é verificar o desempenho de empresas da área da Saúde, com ênfase maior em hospitais, no que concerne ao seu resultado econômico-financeiro, especificamente sua rentabilidade, por meio de comparações entre as OPS e hospitais, e de comparação destes com empresas em geral (EG). Também foram feitas comparações do resultado da atividade e do crescimento da receita entre as empresas da área de Saúde. A hipótese principal que orientou este estudo é que não existem diferenças em termos de rentabilidade entre os maiores (medido pelas receitas) hospitais, OPS e EG. Secundariamente, foram feitas comparações entre os HSFL e os HCFL em relação a seus aspectos econômico-financeiros. Tentou-se também evidenciar o que tem acontecido nesse mercado nos últimos anos, e expor características relevantes, para a presente análise, dos hospitais com e sem finalidade lucrativa. 


\section{O QUE TEM ACONTECIDO NO MERCADO?}

Nesse mercado estão ocorrendo, desde o início dos anos 2000, processos de horizontalização e de verticalização das empresas, com vistas a integrar seus serviços: hospitais têm sido incorporados; montaram ou ampliaram ambulatórios; alguns criaram planos de saúde; outros criaram serviços de reabilitação. OPS, principalmente empresas de medicina de grupo (EMG), têm adquirido hospitais e integrado, parcial ou totalmente, serviços anteriormente realizados por terceiros (principalmente aqueles voltados à assistência médica). Ao mesmo tempo, existe grande número de publicações norteamericanas sobre o tema, pois naquele país esse processo já vem se verificando há algum tempo (BAZZOLI e outros, 2004; BURNS e outros, 2005; EDLIN, 2001; SHORTELL e outros, 2000). Lá, muitas vezes, já é um desafio maior conseguir a integração funcional do que a integração estrutural (PORTER; TEISBERG, 2006).

Verticalizar (fazer a integração vertical) na Saúde significa manter reunidos, sob a mesma organização, diferentes tipos de serviços de saúde, como hospitais, clínicas, empresas de home care (assistência domiciliar), centros de reabilitação, hospices (centros de cuidados paliativos ou para pacientes terminais), centros de educação em saúde e planos de saúde. Também se define a verticalização como a posse comum de duas ou mais empresas, em que uma usa como input o output de outra (BYRNE; WALMUS, 1999). Nessa visão do processo de produção de saúde, o paciente - ou seu estado de saúde - é o produto intermediário transferido de um estágio para outro, a fim de chegar ao produto final desejado, a melhora no estado de saúde do paciente. $\mathrm{Na}$ integração horizontal (horizontalização), organizações similares atuam em conjunto, formando uma cadeia, ao passo que na integração vertical são diferentes etapas da cadeia de valor que estão sob o mesmo comando.

Também existem exemplos de formação de alianças estratégicas, tanto vertical como horizontalmente (FERREIRA, 2000). Como exemplo de aliança vertical, temos as parcerias entre hospitais e OPS. Existem vários casos em que ocorrem parcerias com hospitais independentes, principalmente para a realização de procedimentos de alta complexidade. A implantação desses procedimentos internamente na OPS, nos casos em que ocorre, envolve altos investimentos e não existe necessariamente demanda para garantir economia de escala. O hospital, em geral, já tem o serviço em funcionamento e se beneficia do direcionamento de clientes. Nos EUA, a tendência de integração se firmou desde os anos 1990. Segundo certos autores, os sistemas de saúde multiunidade, em 1994, nos EUA, possuíam, arrendavam ou gerenciavam 53\% dos hospitais que atendiam pacientes com doenças 
agudas (STARKWEATHER; SHROPSHIRE, 1994). Segundo Scott e outros (2000), em 1995, aproximadamente $50 \%$ dos hospitais americanos faziam parte de cadeias ou sistemas integrados. Nos primeiros anos da década de 2000, alguns autores consideram que somente $25 \%$ dos 5 mil hospitais locais americanos e pouco menos da metade dos 17 mil lares de idosos existentes são considerados negócios independentes (HERZLINGER, 2006).

No Brasil, começam a ser descritos casos de integração vertical (ALBUQUERQUE, 2006; VELOSO; MALIK, 2004, 2007). Até 1997 (DINIZ, 1997), a tendência no mercado de EMG era diminuir investimentos em recursos próprios (construção de hospitais) e utilizar mais os recursos credenciados. Na época, a autora evidenciou, por meio de entrevistas com executivos de algumas entre as maiores EMG do país, que $40 \%$ dos serviços a elas ligados lhes pertenciam.

Desde então, porém, ocorreram mudanças no mercado brasileiro. Uma das mais importantes foi a regulamentação dos planos de saúde (em 1998), levando a limitações no aumento nos prêmios, à padronização das coberturas de atendimento e, consequentemente, a uma menor diferenciação. Simultaneamente ocorreu grande ampliação dos direitos dos usuários. Anteriormente, predominavam práticas consideradas abusivas por muitos clientes, e as empresas aumentavam suas receitas por meio da aplicação, no mercado financeiro, dos recursos fornecidos pelos seus usuários. A regulamentação do mercado dos planos de saúde trouxe a necessidade de essas empresas otimizarem sua atuação em seus negócios originais (de saúde), em vez de obterem sua lucratividade no mercado financeiro. Ainda não se encontram pesquisas nacionais sobre estratégias corporativas das EMG após essas mudanças. No entanto, pode-se dizer que desde o ano de 2000 essas empresas estão em forte tendência de integração, tanto em termos de incorporação de prestadores (hospitais e centros médicos próprios) como em relação à contratação de médicos ou equipes médicas. Nesses últimos casos, muitas vezes, por meio da realização de parcerias.

\section{OS HOSPITAIS E A QUESTÃO DA FINALIDADE LUCRATIVA}

Uma característica dos hospitais privados brasileiros que pode ter relevância em um estudo de seus aspectos econômico-financeiro é a natureza jurídica da organização. Na prática, os HCFL são companhias de capital fechado ou empresas de responsabilidade limitada, pois suas ações ou cotas não 
são livremente negociadas. Os HSFL, por sua vez, são, na maioria dos casos, entidades beneficentes sem finalidade lucrativa ou fundações privadas.

De acordo com os dados estatísticos do Ministério da Saúde, aproximadamente $70 \%$ dos hospitais brasileiros são privados, o que perfaz cerca de 5 mil hospitais. Destes, $60 \%$ aproximadamente são empresas privadas (HCFL), e em torno de 39\% são entidade beneficentes ou fundações privadas, ou seja, HSFL (MINISTÉRIO DA SAÚDE, 2010). Os demais são hospitais cadastrados como sindicatos.

Uma das características que pode ter maior impacto nos resultados econômico-financeiro dos HSFL é o fato de eles poderem usufruir de isenções fiscais. No entanto, para obter e manter esses benefícios, pela legislação brasileira, é necessário cumprir uma série de requisitos, que incluem a obtenção e renovação de certificados de filantropia e uma série de etapas a serem seguidas. Em função disso, parte das entidades cadastradas como filantrópicas podem não estar isentas de tributos. Consequentemente, apesar de serem HSFL, ou mesmo filantrópicas, muitas delas podem não dispor de tais benefícios, seja por prazo indeterminado ou por determinados períodos.

Segundo o Ministério da Saúde, cerca de 23\% dos hospitais brasileiros são filantrópicos (MINISTÉRIO DA SAÚDE, 2010). Porém, segundo muitos pesquisadores do tema, sob essa denominação encontram-se diferentes tipos de instituições, desde as tradicionais Santas Casas de Misericórdia até instituições aparentemente lucrativas, que, por meio dos mais diversos artifícios, adquirem a natureza jurídica de filantrópicas (BARBOSA e outros, 2002).

Outra consideração relevante em relação aos HSFL se refere a suas metas econômicofinanceiras. Há quem diga que eles buscam somente um equilíbrio econômico-financeiro e que seu perfil de gasto inclui, por exemplo, maior reinvestimento em equipamentos e serviços. Segundo um grande estudo sobre hospitais filantrópicos, as margens líquidas globais de uma amostra deles, nos anos de 1997, 1998 e 1999, foram respectivamente 6,8\%, 3,8\% e 4,5\%. No mesmo estudo, em um grupo especial de hospitais filantrópicos, reconhecidos como de referência assistencial, a margem líquida ficou em média em 11,1\% nos mesmos anos (BARBOSA e outros, 2002).

O tema é controverso. Facilmente um profissional da área se surpreenderia ao descobrir que alguns hospitais são juridicamente entidades beneficentes. O contrário também é verdadeiro: existem hospitais com forte missão comunitária e religiosa, com gastos anuais em torno de milhões de reais em projetos filantrópicos, mas que juridicamente são empresas com finalidade lucrativa. 


\section{METODOLOGIA}

Para a análise econômico-financeira das empresas foram utilizados dados da publicação Balanço Anual 2007 da Gazeta Mercantil, relativos aos balanços financeiros do exercício de 2006 (GAZETA MERCANTIL, 2007). A revista reúne os balanços publicados das empresas brasileiras e estrangeiras atuantes no Brasil. Na mesma publicação está a compilação de dados dos balanços de hospitais e de planos de saúde, e de empresas de todos os setores da economia. A publicação é conhecida como uma das mais respeitáveis do país. No entanto, ela não é a responsável pela produção dos dados contábeis e, portanto, não tem como garantir a fidedignidade das informações. Para a finalidade deste trabalho, as empresas foram classificadas considerando-se, a princípio, a categorização da revista. Porém, foram também confirmados os registros existentes no Cadastro Nacional de Estabelecimentos de Saúde (CNES) no Ministério da Saúde (MINISTÉRIO DA SAÚDE, 2008b) e na Agência Nacional de Saúde Suplementar (ANS) (MINISTÉRIO DA SAÚDE, 2008a), facilmente acessíveis por meio da internet.

O CNES foi utilizado aqui como fonte para checagem, pois fornecer dados para esse cadastro é obrigatório para todos os estabelecimentos de saúde do país. Trata-se de um conjunto de informações que cada instituição de saúde brasileira deve prestar ao Ministério da Saúde para obter um código a fim de atestar a regularidade de sua situação. O cadastro contém informações, idealmente completas e detalhadas, relacionadas ao tipo de prestação de serviço de saúde, natureza da organização, denominação, personalidade jurídica, aspectos de recursos humanos, área física, equipamentos e serviços ambulatoriais e hospitalares sobre cada uma dessas unidades de saúde. Caso o prestador não mantenha o seu cadastro, ele pode perder o vínculo para o atendimento de clientes de planos de saúde, ou seja, todos os hospitais privados, a princípio, têm interesse em manter o seu cadastro em dia, viabilizando a sua utilização para a classificação da empresa neste trabalho. Algumas dessas empresas também estão horizontalizadas, em redes de hospitais ou de empresas de plano de saúde, sob o nome de uma única OPS ou hospital, na verdade uma holding. Porém, foi considerada, a princípio, a categoria de hospital ou OPS, conforme apresentada pela revista da Gazeta e pelo registro do CNES. As OPS têm registro obrigatório na ANS (MINISTÉRIO DA SAÚDE, 2008a), o que foi útil para confirmações.

As OPS se dividem em quatro tipos: empresas de medicina de grupo, cooperativas, seguradoras especializadas e empresas de autogestão. As duas últimas não têm os seus dados localizáveis na 
publicação. Os dados relativos a elas provavelmente estão inclusos nos dados das patrocinadoras da empresas de autogestão e das holdings das seguradoras.

Antes de iniciar a seleção das empresas, foi necessário remanejá-las, pois muitas OPS estavam listadas entre os hospitais e vice-versa. Isso se fez necessário antes de reordená-las por tamanho de receita. Foram excluídas da amostra, para este trabalho, empresas, OPS e hospitais com dados incompletos e empresas cuja identificação não foi possível pelo seu nome. Também foram excluídas deste trabalho empresas que, apesar de constarem na lista da publicação, estão fora do escopo do trabalho: EMDs como Delboni/Lavoisier, Fleury e Laboratório Álvaro, entre outros; empresas classificadas no CNES como clínicas especializadas ou ambulatórios especializados; planos odontológicos; hospitais da administração direta e indireta; a Sociedade Paulista para o Desenvolvimento da Medicina (SPDM), pois exerce diversas atividades; as Fundações Zerbini e Fundação de Assistência, Estudo e Pesquisa de Uberlândia (FAEPU), pois são fundações de apoio a hospitais de ensino e a outras atividades; o Serviço Social da Construção Civil (Seconci), que exerce também outras atividades; e todas as empresas que não foi possível classificar nas categorias de interesse para o estudo (OPS ou hospitais privados), em função da falta de registro no CNES ou na ANS.

Foram escolhidas para análise as 100 maiores empresas, brasileiras ou estrangeiras, atuantes no Brasil, as 100 maiores OPS e os 100 maiores hospitais, todos definidos pelo critério do tamanho da receita no ano de 2006. Esse critério pareceu adequado, pois privilegia a eficiência da utilização dos ativos para a geração de receitas, ou seja: mais importante do que ter um ativo maior é a eficiência com a qual a empresa o utiliza (PANDELÓ JUNIOR, 2008). Como foram desconsideradas neste trabalho aquelas que não apresentavam todos os dados contábeis principais (balanço patrimonial e resultado do exercício) disponíveis para comparações e o cálculo dos indicadores econômico-financeiros, para a comparação da evolução da receita real só foram utilizadas as 93 maiores (esses dados não estavam presentes em sete das 100 maiores empresas da área de Saúde estudadas).

A natureza da organização hospitalar também foi levantada na ficha do estabelecimento no CNES (MINISTÉRIO DA SAÚDE, 2010). A referida ficha classifica o hospital dentre diversas categorias. Aquelas de interesse para este trabalho são (conforme definições do CNES): (1) empresa: “instituição dotada de personalidade jurídica de direito privado, com patrimônio próprio, para a exploração de atividade econômica"; (2) fundação privada: "instituição dotada de personalidade jurídica autônoma de direito privado, sendo de atividade pública ou beneficente"; e (3) entidade 
beneficente sem fins lucrativos: "entidade associativa civil de direito privado, sem fins lucrativos, que desenvolve atividade beneficente de assistência social". A primeira categoria corresponde aos HCFL e as duas seguintes, aos HSFL. Não foi possível averiguar quais estavam usufruindo de isenções ou imunidades fiscais durante o período de interesse do estudo.

\section{INDICADORES UTILIZADOS}

Para as análises foram utilizados os seguintes indicadores: (1) Retorno sobre o Patrimônio Líquido (ROE); (2) o Retorno sobre o Investimento (ROI); (3) a Margem Líquida (ML); (4) a Geração de Caixa, mais conhecido como Ebitda e, por último, (5) a Evolução Real da Receita (ERR), todos medidos em porcentagens.

A ênfase maior da análise recai sobre os dois primeiros (ROE e ROI). São os que permitem a comparação com os diversos tipos de investimentos em empresas do setor produtivo ou mesmo do mercado financeiro. Eles permitem ao administrador avaliar os resultados financeiros em relação aos retornos dos proprietários e aos investimentos (MARTINS, 2005). O mais utilizado para essa finalidade, e também o mais usado em estudos de estratégia, é o ROI, também chamado de Retorno sobre Ativos (ROA), portanto será o mais valorizado para a finalidade de comparações de rentabilidade neste trabalho.

O ROE, da sigla em inglês Return on Equity, é obtido pela divisão do Resultado Líquido pelo Patrimônio Líquido. Em outras palavras, mede o resultado obtido pelos proprietários da empresa (MARTINS, 2005). É semelhante ao índice Preço/Lucro (P/L) de ações de empresas: quanto menor o $\mathrm{P} / \mathrm{L}$, mais interessante se torna para o investidor colocar o dinheiro naquelas ações. Permite comparação direta com outras aplicações financeiras, como poupança, renda fixa e fundos de investimento (SALIM e outros, 2001). Quanto maior o ROE, melhor.

O ROI, do inglês Return on Investment, é obtido pela divisão do Resultado Líquido pelo Ativo Total. Mede a eficiência global da administração na geração de lucros a partir de seus ativos (MARTINS, 2005). Em outras palavras, representa a produtividade da utilização dos recursos (ATKINSON e outros, 2000), e quanto maior, melhor. Por meio do ROI é possível também determinar o custo máximo de captação (empréstimos e financiamentos) que poderá ser interessante para a 
empresa: se for maior que o ROI, dificilmente a empresa conseguirá repor o valor captado no prazo negociado (SALIM e outros, 2001).

A ML, medida em porcentagem, é a divisão do Resultado Líquido pela Receita Líquida. Representa a medida de lucratividade usual da empresas e evidencia o resultado depois do pagamento de todas as despesas, sejam elas operacionais ou não, e após o pagamento de todos os impostos (LAMEIRA, 2005). Quanto maior for a ML, melhor.

O EBITDA ou LAJIDA é um bom indicador da eficiência operacional. Mede o resultado do negócio da empresa. Representa a geração de fluxo de caixa genuinamente operacional de empresa. Pode ser calculado retirando-se do Lucro Operacional os valores de depreciação e amortizações, de resultado financeiro e de resultado de equivalência patrimonial (GAZETA MERCANTIL, 2007). Aqui será utilizado medido em percentagem, ou seja, a margem LAJIDA. É um indicador cada vez mais usado para a avaliação do desempenho das empresas, e trata-se de um fundamento de valorização da empresa. Quanto maior for, melhor.

A ERR mede o crescimento da receita de empresa. Na publicação consultada, foi medida desconsiderando-se a inflação do período (IGP-M), no caso de demonstrações contábeis elaboradas pela legislação societária, no ano de 2006.

Para as comparações entre HCFL e HSFL, os indicadores utilizados foram: margem LAJIDA, ML e ROI. Essas comparações foram feitas em duas etapas: entre os 50 maiores hospitais (25 HCFL e 25 HSFL) e entre os 100 maiores (51 HSFL e 49 HCFL), seguindo as comparações feitas para as outras dimensões. Dos 51 HSFL, 49 eram entidades beneficentes sem fins lucrativos e dois eram fundações privadas.

Além do estudo descritivo dos dados por meio das medianas e quartis, eles também foram submetidos à análise estatística. Para tanto, foi usado como teste de confiança o teste da mediana. Para garantir a significância dos achados, foi utilizado o teste do qui quadrado ( $\left.\mathrm{X}^{2}\right)$, com a escolha do nível de significância de $5 \%(\mathrm{p}=0,05)$, escolhido de forma a que, tomadas as medianas e as variações das amostras dos três tipos de empresas, se possa afirmar em quais casos se estava diante de diferença estatisticamente significante. Foram usados esses tipos de testes estatísticos não paramétricos porque, embora as variáveis em questão sejam mensuradas no nível intervalar, não é possível garantir que sua distribuição siga uma curva normal. $\mathrm{O}$ trabalho com as medianas também permite diminuir o efeito das distribuições assimétricas e dos outliers (LEVIN, 1987; MCCLAVE; BENSON; SINCICH, 2001). 


\section{RESULTADOS: COMO ESTÃO AS EMPRESAS DE SAÚDE}

Assumidos os critérios para inclusão no presente estudo, as variações das receitas (menores e maiores) de cada um dos grupos das empresas analisadas podem ser vistas na Tabela 1. Nela pode-se verificar grande diferença entre as receitas das 100 maiores empresas do país (EG) em comparação com os 100 maiores hospitais e OPS.

Tabela 1 - Receita das maiores empresas brasileiras ou estrangeiras atuantes no Brasil - 2006

\begin{tabular}{|l|c|c|}
\hline & $\begin{array}{c}\text { Menor } \\
\text { (R\$ mil) }\end{array}$ & $\begin{array}{c}\text { Maior } \\
\text { (R\$ mil) }\end{array}$ \\
\hline $\mathbf{1 0 0}$ maiores & & $21.643 .393,00$ \\
\hline Empresas em Geral & $1.581 .555,00$ & $1.837 .478,00$ \\
\hline Operadoras de Planos de Saúde & $51.523,00$ & $715.758,00$ \\
\hline Hospitais & $12.541,00$ & \\
\hline $\mathbf{5 0}$ maiores & & $21.643 .393,00$ \\
\hline Empresas em Geral & $2.907 .841,00$ & $1.837 .478,00$ \\
\hline Operadoras de Planos de Saúde & $108.201,00$ & $715.758,00$ \\
\hline Hospitais & $40.830,00$ & \\
\hline
\end{tabular}

Fonte: Gazeta Mercantil, 2007.

Notas: Ver texto, para informações sobre critérios de inclusão no estudo.

Pode-se observar, pelo exame dos dados de ROE, na Tabela 2, que, quando avaliados os grupos das 100 maiores, existe diferença estatística significativa entre as EG e as OPS (p = 0,048), e não há diferença real entre essas e os hospitais. Porém, quando avaliadas as 50 maiores empresas, as medianas de ROE de todas ficam mais próximas, embora a diferença entre hospitais e EG ainda seja estatisticamente significante ( $\mathrm{p}=0,046)$. Em uma análise de sensibilidade realizada com os grupos das 25 maiores empresas, não é possível rejeitar a hipótese da igualdade das medianas de ROE nas amostras dos três grupos de empresas. Nesta análise, as medianas de EG, OPS e hospitais estão ainda mais próximas. 
Tabela 2 - ROE de empresas brasileiras ou estrangeiras atuantes no Brasil - 2006

\begin{tabular}{|l|c|c|c|c|}
\hline & Mediana (\%) & & $\mathbf{1}^{\circ}$ Quartil (\%) & $\mathbf{3}^{\circ}$ Quartil (\%) \\
\hline 100 maiores & & & & \\
\hline Empresas em Geral & 18,95 & $\mathrm{a}$ & 7,75 & 35,70 \\
\hline Operadoras de Planos de Saúde & 12,15 & $\mathrm{~b}$ & 1,58 & 30,18 \\
\hline Hospitais & 4,58 & $\mathrm{~b}$ & $-4,79$ & 15,64 \\
\hline 50 maiores & & & & \\
\hline Empresas em Geral & 18,73 & $\mathrm{c}$ & 2,69 & 33,29 \\
\hline Operadoras de Planos de Saúde & 11,16 & $\mathrm{~cd}$ & 1,86 & 24,98 \\
\hline Hospitais & 9,58 & $\mathrm{~d}$ & $-5,70$ & 14,80 \\
\hline
\end{tabular}

Fonte: Gazeta Mercantil, 2007.

Notas: Medianas seguidas das mesmas letras, na vertical, não diferem entre si pelo teste do qui quadrado ( $\mathrm{p}>$ $0,05)$.

Como se vê na Tabela 3, a mesma tendência se verifica na análise do ROI porém com maior clareza: não há diferença significativa entre os três grupos de 50 maiores empresas. Entre as 100 maiores, observa-se o mesmo padrão do que ocorre com o ROE. Isso mostra que as 50 maiores OPS tendem a ter medianas, tanto de ROI quanto de ROE, estatisticamente similares às das maiores EG do país. Os hospitais, quer seja entre os 100, quer seja entre os 50 maiores, têm medianas de ROI similares às de OPS. Não se encontra diferença estatística significativa no ROI dos 50 maiores hospitais em relação às 50 maiores OPS e EG na amostra.

Tabela 3 - ROI de empresas brasileiras ou estrangeiras atuantes no Brasil - 2006

\begin{tabular}{|l|c|c|c|c|}
\hline & Mediana (\%) & & $\mathbf{1}^{\circ}$ Quartil (\%) & $\mathbf{3}^{\circ}$ Quartil (\%) \\
\hline $\mathbf{1 0 0}$ maiores & & & & \\
\hline Empresas em Geral & 7,93 & $\mathrm{a}$ & 2,88 & 14,43 \\
\hline Operadoras de Planos de Saúde & 3,60 & $\mathrm{~b}$ & 0,30 & 8,84 \\
\hline Hospitais & 2,06 & $\mathrm{~b}$ & $-2,10$ & 8,27 \\
\hline $\mathbf{5 0}$ maiores & & & & \\
\hline Empresas em Geral & 6,47 & $\mathrm{c}$ & 1,55 & 14,24 \\
\hline Operadoras de Planos de Saúde & 2,82 & $\mathrm{c}$ & 0,36 & 7,64 \\
\hline Hospitais & 3,25 & $\mathrm{c}$ & $-2,92$ & 8,65 \\
\hline
\end{tabular}

Fonte: Gazeta Mercantil, 2007.

Notas: Medianas seguidas das mesmas letras, na vertical, não diferem entre si pelo teste do qui quadrado ( $\mathrm{p}>$ $0,05)$.

A Margem Líquida das EG, como se observa na Tabela 4, é estatisticamente maior do que a dos hospitais e OPS, seja entre as 100 ( $\mathrm{p}<0,0001$, em ambos os casos) ou entre as 50 maiores 
(respectivamente, $\mathrm{p}=0,0164$ e $\mathrm{p}<0,0001$ ). As OPS e os hospitais não se diferenciam entre si nesse critério, pelas análises efetuadas.

Tabela 4 - Margem líquida de empresas brasileiras ou estrangeiras atuantes no Brasil - 2006

\begin{tabular}{|l|c|c|c|c|}
\hline & Mediana (\%) & & $\mathbf{1}^{\circ}$ Quartil (\%) & $\mathbf{3}^{\circ}$ Quartil (\%) \\
\hline 100 maiores & & & & \\
\hline Empresas em Geral & 8,10 & $\mathrm{a}$ & 2,65 & 18,28 \\
\hline Operadoras de Planos de Saúde & 1,04 & $\mathrm{~b}$ & 0,13 & 3,19 \\
\hline Hospitais & 1,63 & $\mathrm{~b}$ & $-1,56$ & 6,41 \\
\hline 50 maiores & & & & \\
\hline Empresas em Geral & 6,11 & $\mathrm{c}$ & 1,13 & 16,83 \\
\hline Operadoras de Planos de Saúde & 0,87 & $\mathrm{~d}$ & 0,17 & 2,73 \\
\hline Hospitais & 1,35 & $\mathrm{~d}$ & $-1,20$ & 7,21 \\
\hline
\end{tabular}

Fonte: Gazeta Mercantil, 2007.

Notas: Medianas seguidas das mesmas letras, na vertical, não diferem entre si pelo teste do qui quadrado ( $\mathrm{p}>$ $0,05)$.

Uma análise, mostrada na Tabela 5, envolvendo somente OPS e hospitais evidencia que a margem Lajida destes é estatisticamente maior que a daquelas tanto entre as 100 (p < 0,0001) como entre as 50 maiores $(\mathrm{p}=0,0014)$, confirmando o sugerido pela diferença das medianas.

Tabela 5 - Margem Lajida de operadoras de planos de saúde e hospitais no Brasil - 2006

\begin{tabular}{|l|c|c|c|c|}
\hline & Mediana (\%) & & $\mathbf{1}^{\circ}$ Quartil (\%) & $\mathbf{3}^{\circ}$ Quartil (\%) \\
\hline $\mathbf{1 0 0}$ maiores & & & & \\
\hline Operadoras de Planos de Saúde & 0,96 & a & $-0,61$ & 3,07 \\
\hline Hospitais & 4,29 & b & 0,63 & 10,83 \\
\hline $\mathbf{5 0}$ maiores & & & & \\
\hline Operadoras de Planos de Saúde & 1,16 & c & $-0,15$ & 3,11 \\
\hline Hospitais & 3,41 & d & 0,02 & 9,32 \\
\hline
\end{tabular}

Fonte: Gazeta Mercantil, 2007.

Notas: Medianas seguidas das mesmas letras, na vertical, não diferem entre si pelo teste do qui quadrado (p > $0,05)$.

Quanto à ERR, mostrada na Tabela 6, o crescimento da receita das OPS foi maior que o dos hospitais, tanto entre as 93 maiores $(\mathrm{p}=0,0278)$ como entre as 50 maiores $(\mathrm{p}=0,0164)$. 
Tabela 6 - Evolução real da receita de operadoras de planos de saúde e hospitais no Brasil - 2006

\begin{tabular}{|l|c|c|c|c|}
\hline & Mediana (\%) & & $\mathbf{1}^{\circ}$ Quartil (\%) & $\mathbf{3}^{\circ}$ Quartil (\%) \\
\hline $\mathbf{1 0 0}$ maiores & & & & \\
\hline Operadoras de Planos de Saúde & 17,10 & a & 13,20 & 22,40 \\
\hline Hospitais & 14,60 & b & 9,10 & 23,00 \\
\hline $\mathbf{5 0}$ maiores & & & & \\
\hline Operadoras de Planos de Saúde & 17,60 & c & 11,10 & 24,93 \\
\hline Hospitais & 14,15 & d & 8,18 & 19,93 \\
\hline
\end{tabular}

Fonte: Gazeta Mercantil, 2007.

Notas: Medianas seguidas das mesmas letras, na vertical, não diferem entre si pelo teste do qui quadrado ( $\mathrm{p}>$ $0,05)$.

Em relação à comparação dos hospitais em função de sua natureza jurídica, constatou-se que HSFL e HCFL não diferem significativamente entre si em termos de margem LAJIDA, ML e ROI. Os achados são verificáveis tanto ao nível dos 50 maiores, como para os 100 maiores. A publicação da Gazeta oferece também outro indicador, a Incidência Tributária, obtida através da divisão do Lucro Líquido pelo Lucro Operacional. Porém, a análise desse indicador não se revelou útil nesta amostra, uma vez que não exibiu nenhuma diferença estatística significativa para os grupos.

\section{DISCUSSÃO: COMO ENTENDER OS RESULTADOS?}

Sobre o ROE, constata-se que quanto maior o hospital ou a OPS, maior a possibilidade de terem valores similares aos de outras empresas da economia em geral. Ou seja, em relação aos hospitais que têm grandes receitas, é possível que eles sejam tão rentáveis como qualquer outra empresa pode ser.

Quanto à rentabilidade medida pelo ROI, segue na mesma linha: as OPS e os hospitais com grandes receitas, sugerem os dados, tendem a se comportar como as maiores empresas de outros setores da economia. Ou seja, a eficiência geral com que todas essas empresas utilizam os seus ativos é muito semelhante. Esse indicador mostrou que, para o grupo dos 50 maiores hospitais, não existem diferenças em comparação às demais empresas de outros setores, ou seja, as diferenças de rentabilidade podem ocorrer nos casos individuais, a depender de diversas outras variáveis.

Isso faz com que as organizações de saúde podem ser uma alternativa para investimento, pois seu retorno no período, como grupo, foi igual ao de outras empresas. Em alguns poucos casos, superou 
inclusive o Ibovespa do ano em análise. Por outro lado, embora ocorram muitos casos com bom retorno, o risco permanece alto, como se pode verificar pela grande variação observada nas amostras (observações dos quartis). Nesse particular, o que se verifica é que a variação dos retornos de OPS e empresas em geral é bem maior do que a variação nos hospitais. Para as 100 maiores empresas e OPS temos, respectivamente, 91,57 e 77,2 pontos percentuais de amplitude total de ROI, ao passo que os hospitais tiveram 62,04 de amplitude de variação na mesma variável.

Ainda a título de comparação, no ano de 2006, o rendimento da poupança foi de $8,4 \%$; o CDI rendeu 14,95\% e o Ibovespa foi de 33,10\% (PORTES, 2006). Em 2007, essa tendência se inverteu, e rentabilidade de algumas empresas produtivas já supera aplicações em Fundos DI (PRADO, 2007). Desde então, têm ocorrido mudanças na economia brasileira e no mercado financeiro globalmente, e este último vem apresentando grande volatilidade a partir do primeiro trimestre de 2008.

Por outro lado, a ML, que na verdade é influenciada pelas características de cada setor (LAMEIRA, 2005), não é uma medida adequada para a comparação da rentabilidade entre diferentes possibilidades de investimento. $\mathrm{Na}$ verdade, ela mede a lucratividade, e foi colocada aqui complementando a análise de rentabilidade das empresas. De qualquer forma, ficou demonstrado que as empresas de saúde têm uma lucratividade menor que as empresas em geral. Também se evidenciou que os hospitais e as OPS não são diferentes nesse critério, apesar de à primeira vista os hospitais terem uma mediana discretamente maior.

Já em relação à geração de caixa (margem LAJIDA), medida da receita gerada pela atividade principal das empresas, os hospitais apresentaram desempenho melhor que as OPS. Outras publicações mostram também melhores resultados de geração de caixa para os hospitais. Na verdade, ainda mais altos que os encontrados nas fontes de dados utilizadas para este estudo: em torno de $16,5 \%$, no ano de 2006, para os hospitais membros da Associação Nacional dos Hospitais Privados (ANAHP, 2007), entidade que reúne 36 hospitais brasileiros, ou seja, um grupo mais reduzido.

Pode-se dizer que a operação dos hospitais gera mais caixa, em termos de margem, que a operação das OPS (excluindo, portanto, fatores como despesas financeiras, impostos, depreciações e amortizações). Isso pode sugerir que os hospitais devem ter mais dificuldades relacionadas a encargos financeiros, despesas não operacionais ou investimentos, quando comparados com as OPS.

Por outro lado, as análises mostram que as OPS estudadas tiveram comprovadamente maior evolução real da receita do que os hospitais no ano de 2006. Vale lembrar que nesse mesmo ano o crescimento do PIB foi de 3,7\% (INSTITUTO BRASILEIRO DE GEOGRAFIA E ESTATÍSTICA, 
2007) e que, segundo a publicação da Gazeta Mercantil, o crescimento verificado nas empresas do setor de serviços foi de 14\% (GAZETA MERCANTIL, 2007). Como o acréscimo de receita ocorre por crescimento orgânico ou por fusões e aquisições entre as empresas, e como se tem evidenciado em outros estudos que este mercado (OPS) está cada vez mais competitivo, com pouco crescimento, e que existe uma tendência à diminuição do número das empresas do setor, pode-se concluir que nas OPS está em andamento uma tendência de concentração. Os hospitais, por seu turno, com evolução menor da receita, acompanharam o crescimento verificado no setor de serviços, que, por sinal, foi um dos setores que impulsionaram o crescimento do PIB brasileiro naquele ano (INSTITUTO BRASILEIRO DE GEOGRAFIA E ESTATÍSTICA, 2007).

Quanto às comparações entre hospitais de natureza diferente, as evidências mostram que não há diferenças entre esses hospitais no que diz respeito às principais medidas econômico-financeiras. Isso pode mostrar que não devem existir diferenças em termos das metas que essas organizações buscam. Isso pode fortalecer uma visão de que não existem muitas diferenças entre elas. Os achados sugerem que provavelmente os hospitais, independentemente de sua natureza, sofrem (e exercem) as mesmas pressões técnicas e de mercado. A esse respeito, um grupo prolífico de autores da área de Saúde afirma: “... se são instituições com ou sem fins lucrativos, essa é uma distinção que só interessa às autoridades fiscais" (CHRISTENSEN; GROSSMAN; HWANG, 2008, p. 189). De qualquer forma, o tema permanece em debate. Em síntese, os dados sugerem que a variável natureza da organização hospitalar não parece ser um bom preditor do que pode ocorrer em termos de margens líquidas da atividade e de retorno sobre os ativos de um determinado hospital.

\section{CONCLUSÃO}

Segundo o presente estudo, grandes hospitais podem ser tão rentáveis como outras empresas. Mais precisamente, não foi possível rejeitar a hipótese que não existem diferenças em termos de rentabilidade entre hospitais, OPS e EG, quando se analisam aquelas que têm maiores receitas. Quanto maior as empresas, maior a dificuldade para rejeitar essa hipótese, levando a crer que o tamanho da receita das empresas é um fator com influência na rentabilidade das empresas analisadas. Ainda mais que é grande a diferença de receita entre as empresas da área de Saúde e da economia em geral. 
O senso comum leva a crer que os hospitais em geral não são empreendimentos rentáveis. O que o estudo realizado mostra é que se são ou não rentáveis depende de outras variáveis (volume de receita, por exemplo, entre outras). O fato de serem organizações da área de Saúde não determina necessariamente seus resultados. Pelo menos, pode-se dizer que os resultados dos maiores hospitais não são tão diferentes dos das empresas de outros setores, como se costuma acreditar ou afirmar fora do mundo da Saúde. Possivelmente o tamanho do hospital representa uma variável com forte influência (podendo ser considerado um fator confundidor) na sua rentabilidade, no sentido de que a receita da empresa pode se relacionar fortemente - e independentemente do fato de ser um hospital - com o seu retorno sobre o capital.

Para concluir, e retomando uma visão mais ampla, é importante lembrar que as organizações da área de Saúde, principalmente os hospitais, não têm seu desempenho medido somente por seus aspectos econômicos e financeiros. "Resultados financeiros são uma consequência, não uma meta em si e por si mesma. Um confortável superávit operacional não pode compensar a mediocridade do atendimento aos pacientes" (PORTER; TEISBERG, 2006, p. 156).

\section{LIMITAÇÕES, SUGESTÕES E RECOMENDAÇÕES}

Pode-se apontar como limitação do estudo o fato de a análise ter sido feita apenas para um ano, o que pode ser corrigido com o acompanhamento dos próximos anos, a fim de diagnosticar novas tendências.

Surge como variável relevante o tamanho da receita da organização. Para se controlar o efeito desse fator, seria desejável um estudo que pareasse os três tipos de empresas por tamanho de receita, de maneira a reduzir sua influência.

Como ficou evidenciado que os hospitais são empresas que podem ser rentáveis e como muitos dos hospitais com receita menor (aqueles que sequer estão incluídos entre os 100 maiores) também têm alta rentabilidade (com ROI acima de 30\% no ano de 2006, para alguns), cabem ainda estudos sobre os fatores específicos do hospital, ou do seu contexto, que levaram a tal desempenho. Independentemente do tamanho de sua receita, possivelmente hospitais que atuam em nichos específicos, ou em regiões com alta demanda, ou ainda com controle sobre recursos escassos ou em um contexto onde ocorra a conjugação de vários fatores ou características, podem alcançar altos valores para esse indicador. De qualquer forma, essa é uma fértil área de pesquisa. 


\section{REFERÊNCIAS}

ALBUQUERQUE, G. M. Integração vertical na medicina suplementar: contexto e competências organizacionais. Dissertação em Mestrado em Administração, Universidade de São Paulo, São Paulo, 2006.

ASSOCIAÇÃO NACIONAL DOS HOSPITAIS PRIVADOS. Revista SINHA. Sistema Integrado de Indicadores Hospitalares ANAHP. Balanços 2002 a 2006. São Paulo: Companhia de Notícias, 2007.

ATKINSON, A. A.; BANKER, R. D.; KAPLAN, R. S.; YOUNG, S. M. Management Accounting. $3^{\text {rd }}$ edition. Upper Saddle River, NJ: Prentice Hall, 2000.

BARBOSA, P. R.; PORTElA, M. C; UGÁ, M. A. D.; VASCONCELlOS, M. M.; LIMA, S. M. L.; GERSCHMAN, S. V. Hospitais filantrópicos no Brasil. Rio de Janeiro: BNDES, 2002.

BAZZOLI, G. J.; CHAN, B.; SHORTELL, S. M.; D'AUNNO, T. The financial performance of hospitals belonging to health networks and systems. Inquiry, v. 37, n. 3, p. 234-252, 2000.

BURNS, L. R.; WALSTON, S. L.; ALEXANDER, J. A.; ZUCKERMAN, H. S.; ANDERSEN, R. M.; TORRENS, P. R.; HILBERMAN, D. Just how integrated delivery systems? Results from a national survey. Health Care Management Review, v. 26, n. 1, p. 20, Winter 2001.

BYRNE, M. M; WALMUS, A. C. Incentives for vertical integration in healthcare: the effect of reimbursement systems. Journal of Healthcare Management, v. 44, n. 1, p. 34-46, Jan/Feb. 1999.

CHRISTENSEN, C. M; GROSSMAN, J. H; HWANG, J. The Innovator's Prescription: A Disruptive Solution for Health Care. New York: McGraw-Hill, 2008. 
CORREA, L. R. C. Os hospitais de pequeno porte do Sistema Único de Saúde e a segurança do paciente. 2009. Dissertação de Mestrado em Administração de Empresas, Escola de Administração de Empresas de São Paulo da Fundação Getulio Vargas, São Paulo, 2009.

DINIZ, D. M. F. Estudo exploratório em algumas empresas de medicina de grupo na cidade de São Paulo: formas de atuação no mercado empresarial. Dissertação de Mestrado em Administração de Empresas, Escola de Administração de Empresas da Fundação Getulio Vargas, São Paulo, 1997.

EDLIN, M. For the modern IDS, less is often more. Managed Healthcare Executive, v. 11, n. 3, p. 2630, Mar. 2001.

FERREIRA, J. H. G. Alianças estratégicas em hospitais privados: estudo de caso com oito hospitais. 2000. Tese de Doutorado em Saúde Pública, Faculdade de Saúde Pública, Universidade de São Paulo, São Paulo, 2000.

GAZETA MERCANTIL. Balanço Anual 2007. São Paulo: Editora JB, n. 31, setembro 2007.

HERZLINGER, R. E. Why innovation in health care is so hard. Harvard Business Review, v. 84, n. 5, p. 58-66, May 2006.

INSTITUTO BRASILEIRO DE GEOGRAFIA E ESTATÍSTICA. PIB cresce 3,7\% e chega a R \$ 2,3 trilhões em 2006. 2007. Disponível em:

$<$ http://www.ibge.gov.br/home/presidencia/noticias/noticia_visualiza.php?id_noticia=850\&id_pagina= 1>. Acesso em 15.03.2008.

LAMEIRA, V. (Coord) Negócios em Bolsa de Valores. São Paulo: Alaúde Editorial, 2005.

LEVIN, J. Estatística aplicada a ciências humanas. 2a . edição. São Paulo: Editora Harbra, 1987.

MARTINS, D. Administração financeira hospitalar. São Paulo: Atlas, 2005. 
MCCLAVE, J. T; BENSON, P. G; SINCICH, T. Statistics for Business and Economics. $8^{\text {th }}$ edition. Upper Saddle River, NJ: Prentice Hall, 2001.

MINISTÉRIO DA SAÚDE. Agência Nacional de Saúde Suplementar. Atualizado em: 14 mar. 2008. Disponível em: http://www.ans.gov.br/portalv4/site/home/default.asp. Acesso em 15.03.2008.

MINISTÉRIO DA SAÚDE. CNES.Net. Cadastro Nacional de Estabelecimentos de Saúde. Atualizado em: 14 mar. 2008. Disponível em:

http://cnes.datasus.gov.br/Index.asp?Configuracao=1024\&bro=Microsoft\%20Internet\%20Explorer. Acesso em 15.03.2008.

MINISTÉRIO DA SAÚDE. CNES.Net. Cadastro Nacional de Estabelecimentos de Saúde. Atualizado em: 20 fev. 2010. Disponível em:

http://cnes.datasus.gov.br/Index.asp?Configuracao=1024\&bro=Microsoft\%20Internet\%20Explorer. Acesso em 20.02.2010.

PANDELÓ JUNIOR, D. R. Análise do Desempenho do Setor Bancário versus Setor Produtivo. Valor Econômico, São Paulo, 11 fev. 2008. Caderno A, p. 8.

PORTER, M. E; TEISBERG, E. O. Redefining Health Care: Creating Value-Based Competition on Results. Boston: Harvard Business School Press, 2006.

PORTES, I. Poupança deve ter ganho real de 5,6\%, o maior desde 1999. Folha de S.Paulo, São Paulo, 29 dez. 2006. Caderno Dinheiro.

PRADO, M. Ganho da indústria já supera aplicações. Folha de S.Paulo, São Paulo, 02 set. 2007. Caderno Dinheiro.

SALIM, C. S. e outros. Construindo planos de negócios. Rio de Janeiro: Campus, 2001. 
SHORTELL, S. M. e outros. Integrating health care delivery. Health Forum Journal, v. 43, n. 6, p. 3539, Nov/Dec. 2000.

STARKWEATHER, D. B; SHROPSHIRE, D. G. Management effectiveness. In: TAYLOR, R. J; TAYLOR, S. B. (Org) The AUPHA Manual of Health Services Management. Maryland: Aspen Publishers, 1994. Cap. 2, p. 19-44.

VECINA NETO, G; MALIK, A. M. Tendências na assistência hospitalar. Ciência \& Saúde Coletiva, v. 12, n. 4, p. 825-839, 2007.

VELOSO, G. G; MALIK, A. M. Aplicação de modelos de decisão make or buy em hospitais: análise de terceirizações em serviços de apoio diagnóstico e terapêutico em hospitais privados do município de São Paulo. In: ENCONTRO DE ESTUDOS ORGANIZACIONAIS, 2004, São Paulo. Anais. São Paulo: EnEO, 2004.

VELOSO, G. G; MALIK, A. M. Modern hospitals are networks of organizations. Einstein, v. 5 , n. 1, p. 10-15, 2007. 